\title{
Correction To: Case Study in the Design of a Surrogate Solution for Use in Biopharmaceutical Drug Product Process Development
}

\author{
Kevin Boksa, ${ }^{1}$ Peter Walsh, ${ }^{2,4}$ and Ambarish Shah $^{3}$
}

published online 10 February 2021

Correction to: AAPS PharmSciTech volume 22, Article number: 32 (2021)

https://doi.org/10.1208/s12249-020-01881-z

Upon publication, formatting issues with Table II occurred.

- The "Citric acid row is in error."

- In the Tg' column the unit, celsius has been removed in place of "reference" as well as the (\%) in the solubility column.

- The reference names were not intended to be placed in the table itself.

- The citric acid Tg' value was also not updated during the proofing process.
The corrected table is below.

\begin{tabular}{|c|c|c|}
\hline Molecule Evaluated & Tg' reference & Solubility in water reference \\
\hline Human Serum Albumin & 20 - Gearing & \\
\hline Bovine serum albumin & 21 - Wang & \\
\hline Dextran 70 & 23 - Her & \\
\hline Hydroxyethyl starch & 21 - Wang & \\
\hline Ficoll $70 \mathrm{~K}$ & 23 - Her & \\
\hline PVP K40 & 23 - Her & \\
\hline Raffinose & 21 - Wang & 22 - Yalkowski \\
\hline Mannitol & 21 - Wang & 22 - Yalkowski \\
\hline Lactose monohydrate & 23 - Her & 22 - Yalkowski \\
\hline Histidine & 21 - Wang & 22 - Yalkowski \\
\hline Sucrose & 21 - Wang & 22 - Yalkowski \\
\hline Trehalose & 20 - Gearing & 22 - Yalkowski \\
\hline Citric acid & 21 - Wang & 22 - Yalkowski \\
\hline Tromethamine (tris) & 21 - Wang & 22 - Yalkowski \\
\hline Sorbitol & 21 - Wang & 22 - Yalkowski \\
\hline Glycine & 21 - Wang & 22 - Yalkowski \\
\hline
\end{tabular}

Publisher's NoteSpringer Nature remains neutral with regard to jurisdictional claims in published maps and institutional affiliations.
The online version of the original article can be found at https:// doi.org/10.1208/s12249-020-01881-z

\footnotetext{
${ }^{1}$ Corteva Agriscience, 9330 Zionsville Rd, Indianapolis, Indiana 46268, USA.

${ }^{2}$ Bristol Myers Squibb, 556 Morris Ave., Summit, NJ 07901, USA.

${ }^{3}$ Seqirus, 475 Green Oaks Pkwy, Holly Springs, North Carolina 27540, USA.

${ }^{4}$ To whom correspondence should be addressed. (e-mail: peter.walsh1@bms.com; peterandrewwalsh@gmail.com)
} 